\title{
Virgin Islands, U.S.
}

National Cancer Institute

\section{Source}

National Cancer Institute. Virgin Islands, U.S.. NCI Thesaurus. Code C17255.

A group of islands between the Caribbean Sea and the North Atlantic Ocean, east of Puerto Rico and west of the British Virg in Islands. 